\title{
PREDICTORS OF THE FEELING OF STRESS IN THE AVIATION SECTOR
}

\author{
Magdalena Ślazyk-Sobol ${ }^{1}$, Małgorzata Dobrowolska ${ }^{2}$, Maria Flakus ${ }^{3}$ \\ ${ }^{1}$ University of Wroclaw, Wrocław, Poland \\ Institute of Psychology \\ ${ }^{2}$ Silesian University of Technology, Gliwice, Poland \\ Institute of Education and Communication Research \\ ${ }^{3}$ University of Silesia in Katowice, Katowice, Poland \\ Institute of Psychology
}

\begin{abstract}
Background: Employees in the aviation sector constitute an especially interesting professional group due to a lack of empirical data on their psychological functioning, and the fact that this industry is currently experiencing a phase of dynamic development. However, taking into consideration the automation and specific qualities of the sector, human resources should be given much more attention as they are constantly challenged and face diverse difficulties at work while cooperating in various organic and non-organic teams. Material and Methods: The study included 326 employees of Pyrzowice (Poland), Szymany (Poland), and Košice (Slovakia) airports (however, people employed at the Polish airports were predominant, $\mathrm{N}=250$ ). The average age of the participants was 39.3 years, and the sample was predominantly male $(\mathrm{N}=278,85.3 \%)$. During the research procedure, the following questionnaires were used: the Feeling of Threat in the Workplace Questionnaire, the Feeling of Stress Questionnaire, the 10-Item Personality Inventory, and the Mini-COPE Stress Inventory. Results: The regression analysis indicated that personality variables did not allow for predicting the level of stress. However, the helplessness-oriented style $(\beta=0.191, p=0.004)$, avoidant behaviors $(\beta=0.244, p<0.001)$, and the feeling of threat $(\beta=0.147, p=0.009)$ were significant predictors of the feeling of stress, and their high level corresponded with a higher level of stress. The final model explained $23 \%$ of the total variance in the feeling of stress. Conclusions: Based on the results, practical recommendations should concern developing employees' skills related to monitoring stressors and strengthening proactivity in difficult or threatening situations. Such proactive strategies may decrease the tendency to use avoidant and helplessness-oriented behaviors that may cause a higher level of stress perceived by employees. Also, the authors recommend providing training and support using some cognitive behavioral techniques because it seems that the regular application of those methods supports the development of agency and control while facing challenging situations. Med Pr. 2021;72(5):467-77
\end{abstract}

Key words: stress-coping styles, personality traits, the feeling of threat, the feeling of stress, aviation sector, 4.0 employees

Corresponding author: Magdalena Ślazyk-Sobol, University of Wrocław, Institute of Psychology, Dawida 1, 50-529 Wrocław, Poland, e-mail: magdalena.slazyk-sobol@uwr.edu.pl Received: November 2, 2020, accepted: May 31, 2021

\section{INTRODUCTION}

The importance of developing and applying strategies helpful in maintaining the health of employees and organizations has recently become more prominent. Such procedures are an essential ingredient of sustainable development, in which particular attention has been paid to working healthily and nurturing healthy and motivated employees [1]. In particular, one of the main problems related to the psychological elements of sustainability is the level of personal integration of employees into the organizations. Among various scenarios, this integration may decrease when a particular person experiences feelings of stress or threat. These feelings may be particularly severe for people working in sectors where risks are borne daily, for example, in the aviation sector. Also, feelings of stress and threat may be increased by certain individual dispositions and factors. Therefore, the identification of those predisposing risk factors, with a strong focus on maintaining the well-being and psychological health of employees, seems to be essential while discussing sustainable development in organizations [2].

In the case of work, various risks and threats related to the workplace can induce stress, especially in industries with a high degree of automation. The aviation sector represents the type of work called "Work 4.0," 
characterized by cutting-edge technologies, automation, and industry 4.0. This type of work concerns different job positions; some include direct contact with technology and engineering. Therefore, it is full of accidents, technical problems, and hazards related to complex equipment and technology. All these factors constitute specific circumstances of work-related stressors.

The term "stress" refers to the external circumstances, requirements, burdens, or difficult situations, or may describe unpleasant emotional experiences, tension, and discomfort $[3,4]$. These 2 ways of understanding stress are present in theoretical papers and studies on stress.

Contemporary concepts of psychological stress do not locate sources of stress only in an individual or their environment, but rather point out a specific relationship (interaction, transaction) between a subject and their environment $[5,6]$. The classical, and at the same time still valid, cognitive-interactional stress paradigm developed by Lazarus also concentrates on human activity in a particular situational context. According to the author, a transaction between a person and their environment creates a new quality that changes persistently. It is also cognitively evaluated by the subject and dynamic (initial evaluation). The individual evaluates elements from the environment which are prominent from the perspective of their well-being. Lazarus and Folkman [3] defined stress in terms of interaction between a person and the environment. If this interaction is evaluated by the individual as burdensome, exceeding their resources or threatening their well-being, it results in experiencing stress.

A stress transaction in the initial evaluation can be interpreted as a harm/loss, a threat, or a challenge. In each of these cases, certain emotions can occur: a harm/loss perception triggers anger, regret, or sadness; a threat is related to fear, anxiety, or worry; and challenges may facilitate positive emotions, such as hope, excitement, and joy, but also negative emotions similar to those occurring while experiencing threats. The secondary evaluation is the next cognitive process occurring when the individual assesses the relationship as stressful. It is related to interpreting the sources of stress and estimating personal resources. If the individual evaluates their resources as sufficient to manage the stressors, the primary evaluation can be changed from a threat to a challenge. In this way, the secondary assessment becomes the stage of analysis where an activity directed to a change of the stress transaction can be established.

Lazarus and Folkman [3] described coping with stress as changing cognitive and behavioral personal efforts which aim to comply with specific external and internal requirements. These requirements may be experienced as a burden, exceeding the resources of the individual. The first coping strategy is problemfocused coping (it has an instrumental, task-oriented function). It aims at improving the relationship between environmental requirements and personal capabilities. The other style is connected with emotional self-regulation and aims at decreasing unpleasant tension and soothing negative emotions.

The postponed effects of stress experienced in a workplace can lead to a weakened immunity of an individual to exhaustion [7].

In the area of professional stress and burnout, experiencing chronic organizational stress is seen as a trigger for further symptoms: exhaustion (which is the body response to stress), cynicism, and a gradually decreasing feeling of self-effectiveness [5-7]. Individual strategies applied when experiencing puzzling situations and emotions are a crucial aspect in the context of successful coping with stress. Despite many scientific disputes on dealing with stress in the area of workplace and organizational psychology [8], the approach presented by Scheier and Carver [9] has maintained a high level of popularity; it understands coping as a result of qualities of both an individual and a situation.

Coping styles encompass both a stable disposition to solve difficult situations and tendencies to use active and avoidant strategies concentrated on problems and emotions. The strategies of coping with stress are determined by the following factors: the qualities of the situation experienced, the perception of the conditions, and also personal qualities and resources. The last factor plays a salient role in dealing with stressful events. Several external resources can be pointed out which support an individual, belonging to their closest surrounding, and also internal determinants, i.e., their individual qualities [10]. These personality factors, treated as relatively stable parameters of human functioning, are significantly connected with the specific reaction of an individual to experiencing psychological stress [11-13]. The most popular and empirically verified concept of personality is the Big Five model by Costa and McCrae [14-16].

In the Big Five model, extraversion (vs. introversion) describes a tendency towards social interactions, energy, activity, and experiencing positive emotions. High extraversion typically indicates friendliness, being active and optimistic, sociable and communicative, a tendency 
to have fun, and searching for stimuli. Low extraversion (introversion) is related to the distance in social contacts, shyness, a lack of optimism, or a preference to be alone [15-17]. The next factor of the model, agreeableness, describes the tendency towards a positive vs. negative attitude to other people, connected with altruism vs. antagonism. High agreeableness typically indicates likability, a tendency to help others, straightforwardness, honesty, meekness and kindness, modesty, and sensibility for others. Notably, low agreeableness typically indicates egocentrism, competition-oriented attitude, and sometimes aggression and coldness in social interactions $[15,16]$. Another trait is conscientiousness, which describes an attitude towards goal-oriented actions, and is related to being organized, motivated, and persistent. High conscientiousness typically indicates high achievement orientation, high motivation, and persistence in pursuing and achieving one's goals. Low conscientiousness indicates poorly specified life goals, low preciseness, and a low level of achievement motivation, hedonism, impulsivity in decision making, and spontaneity [15-17].

In the Big Five model, emotional stability (vs. neuroticism) describes a tendency towards experiencing negative emotions, such as discontent, confusion, guilt, fear, and anger. High emotional stability (low neuroticism) typically indicates effective adaptation to emotionally challenging situations, and the ability to manage stress without tension, irritation, or doubts. High neuroticism also represents a lower ability to control one's instincts, struggling with stress, a tendency towards worrying, shyness, and confusion while being with others, and reactions driven by fear and tension [16]. The last factor of the model is openness, which describes a tendency towards searching for new life experiences and towards their positive evaluation, tolerance towards novelty, and cognitive curiosity. High openness typically represents curiosity, creativity, imagination, unconventional thinking, and having independent opinions. Low openness indicates conventional thinking, conservativeness, holding traditional values, pragmatic interests, and a preference for socially accepted ways of acting [15].

The feeling of threat means experiencing anxiety related to the results of potential or real dangers. Facing real professional situations generates a specific cognitive-imaginative picture which encompasses the whole set of experiences connected with a working place. It can contain various elements: internal discomfort and fear of potentially dangerous situations in the workplace (e.g., explosions, fire), and worries related to real and current threats in everyday work. Additionally, the construct of the feeling of threat contains potential actions resulting from threat avoidance (at the behavioral and cognitive level, e.g., being repeatedly alert and aware of dangerous elements of the working environment). In the authors opinion, such an understanding of the feeling of threat can be related to generating additional stress, which is due to the relationship between a frequent feeling of threat at work (threat to one's life, health, interpersonal relations) and a frequent feeling of professional stress $[3,4]$.

\section{Present study}

The employees in the aviation sector are a very hermetic professional group. At the same time, their perception of phenomena and psychological mechanisms has not been studied well yet. The effectiveness of their everyday work is based on professionalism and cooperation, and also on the effective managing of difficult and dangerous situations. It should be emphasized that their work is characterized by advancing automation and robotization of their organizational environment. The study aimed to measure personality variables, stress coping styles, and the feeling of threat among the employees of the Polish and Slovak aviation sector.

The following research questions were formulated:

What are the relationships between the personality variables, stress coping styles, and the feeling of threat?

What are the relationships between the variables and the overall feeling of stress?

Which of the variables will enable predicting the level of experienced stress?

\section{MATERIAL AND METHODS}

\section{Sample of employees}

All the missing data (e.g., incomplete questionnaires, no demographic variables, etc.) were excluded from the analysis. Overall, 125 records were excluded. Finally, the study included 326 persons employed in the aviation sector (in positions such as: a safety specialist, an aircraft mechanic, an assistant mechanic, an aircraft engineer, a manager, a manual worker, an aviation structural mechanic, an airport firefighter, a chemical technician and others). The exact information about the occupational category of each participant was not collected in the presented study.

The average age of the participants was 39.3 years $(\mathrm{SD}=10.7)$. They had an average total work experience of 16.7 years $(\mathrm{SD}=11.3)$, and the average experience in their respective positions was 9.01 years $(S D=2.5)$. 
The sample consisted mostly of men $(\mathrm{N}=278,85.3 \%)$ working at the following airports: Pyrzowice and Szymany (Poland), and Košice (Slovakia). People employed at the Polish airports $(\mathrm{N}=250)$ were predominant.

Although the airports involved in the study differ in size and the number of employees, they are similar when it comes to the level of automation and technologies used in daily practice. Before starting the quantitative research, interviews with the management staff of selected airports were conducted. Working and employment conditions turned out to be very similar, and the issues of remuneration, development and promotion opportunities were also alike. All measures were administered in the Polish and Slovak languages. All the subjects were notified about the goal of the research, and they agreed to participate in it. While conducting the study, the recommendations of the Declaration of Helsinki were followed.

\section{Questionnaires and \\ psychological evaluation methods \\ Feeling of threat}

In the study, the authors used the Feeling of Threat in the Workplace Questionnaire by Mamcarz [18]. This instrument is used to measure the feeling of threat as the experiencing of fears connected with the effects of current/potential dangers in the workplace. It consists of 54 statements with a 5 -point Likert scale $(1-$ never, 5 - very often; example items: "When I'm at work, it's difficult for me to concentrate on anything" or "I am not able to fully do my work through thoughts that come to me"). It measures the following 3 indicators: internal discomfort, a fear of current dangers, and a tendency to avoid threats.

In this study, the scale yielded good or at least satisfactory internal consistency (for Polish and Slovak samples, respectively: the overall scale: $\alpha=0.96$ and $\alpha=0.96$; internal discomfort: $\alpha=0.95$ and $\alpha=0.95$; a fear of current dangers: $\alpha=0.85$ and $\alpha=0.91$; and a tendency to avoid threats: $\alpha=0.71$ and $\alpha=0.70$ ).

\section{Feeling of stress}

To measure the feeling of stress, the authors used the Feeling of Stress Questionnaire by Plopa and Makarowski $[19,20]$. This instrument consists of 27 items with a 5-point Likert scale ( 1 - definitely false, 5 - definitely true; example items: "I feel anxiety and more and more things annoy me" or "I have difficulty relaxing, although I try to"). The items create 3 scales. The first is the scale of emotional tension related to experiencing high levels of anxiety, uncertainty, tiredness, and resource depletion. The second is external stress, described as experiencing stress in situations which exceed the personal abilities of an individual (e.g., inadequate tasks or area of work), and as the feeling of being unfairly assessed and evaluated at work. This dimension is characterized by experiencing helplessness and loneliness. The third measured dimension is the level of intrapsychic stress manifested in the inability to cope with the experienced emotional states. This scale expresses pessimism and a negative perception of oneself and the outside world.

In this study, the scale yielded a satisfactory reliability level (for Polish and Slovak samples, respectively: the overall scale: $\alpha=0.85$ and $\alpha=0.86$; emotional tension: $\alpha=0.76$ and $\alpha=0.70$; external stress: $\alpha=0.70$ and $\alpha=0.72$; and intrapsychic stress: $\alpha=0.73$ and $\alpha=0.69$ ).

\section{Big Five personality dimensions}

The 10-Item Personality Inventory (TIPI) [17] was selected for measuring personality traits. Studies show that this 2 -minute test is a relatively accurate and reliable instrument for personality measurement in scientific studies.

Thanks to the adequate psychometric properties of the TIPI-PL scale [17], it is possible to obtain a personality representation of sufficient precision for scientific use. Additionally, the conciseness of the inventory allows for a personality assessment to be carried out in a very short time. The TIPI is based on a self-description using simple adjectives and phrases. It consists of 10 statements beginning with "I see myself as." The participant is asked to assign each statement a number on a 7-point Likert scale ( 1 - disagree strongly, 7 - agree strongly; example items: "I see myself as a person who likes the company of others, active and optimistic" or "I see myself as a poorly organized, careless person"). The phrases used in the test originate from the existing measuring methods of the Big Five personality dimensions $[3,21]$.

Considering the fact that the TIPI-PL used only 2 phrases to measure each of the personality dimensions, Cronbach's a internal consistency coefficients were mostly low (for Polish and Slovak samples, respectively: extraversion: $\alpha=0.34$ and $\alpha=0.35$; agreeableness: $\alpha=0.30$ and $\alpha=0.32$; conscientiousness: $\alpha=0.52$ and $\alpha=0.52$; emotional stability: $\alpha=0.42$ and $\alpha=0.44$; and openness: $\alpha=0.20$ and $\alpha=0.22$ ). Therefore, as an additional measure of consistency of the scale, the authors used the intercorrelations between items, which 
denote a moderate level of correlations between items (for Polish and Slovak samples, respectively: extraversion: $r=0.32$ and $r=0.34$; agreeableness: $r=0.34$ and $r=0.40$; conscientiousness: $r=0.36$ and $r=0.38$; emotional stability: $\mathrm{r}=0.31$ and $\mathrm{r}=0.29$; and openness: $\mathrm{r}=$ 0.30 and $\mathrm{r}=0.44$ ).

\section{Coping styles}

The measurement of the coping style was performed using the Mini-COPE Inventory for Measuring Coping with Stress by Juczyński and Ogińska-Bulik [20], based on the concepts by Carver et al. [22]. The Mini-COPE is intended to be used with adults, with or without a medical condition. It consists of 28 statements spanning 14 strategies (2 statements per strategy), which are grouped into 7 factors: active coping, helplessness, seeking support, avoidant behaviors, acceptance, humor, and turning to religion. The method is most often used for measuring the dispositional coping, i.e., for assessing the typical reactions and emotions in highly stressful situations.

The items of this instrument begin with the phrase: "When I am in a very difficult situation, I usually..." and are rated on a 4-point scale (0 - "I almost never do this," 3 - "I almost always do this;" example items: "I do work or other activities so that I don't think about it" or "I get emotional support from others").

In this study, the scale yielded a mostly borderline internal consistency level (for Polish and Slovak samples, respectively: active coping: $\alpha=0.75$ and $\alpha=0.69$; helplessness: $\alpha=0.62$ and $\alpha=0.79$; seeking support: $\alpha=0.60$ and $\alpha=0.68$; avoidant behaviors: $\alpha=0.65$ and $\alpha=0.60$; acceptance: $\alpha=0.61$ and $\alpha=0.60$; humor: $\alpha=0.60$ and $\alpha=0.65$; and turning to religion: $\alpha=60$ and $\alpha=0.62$ ).

\section{Statistical software}

The authors applied all statistical analyses using JASP (version 0.14) software [23]. The software is an independent and open-source project supported by the University of Amsterdam.

\section{RESULTS}

The descriptive statistics for the analyzed variables are presented in Table 1.

According to the fact that the study was conducted in 2 countries, the authors checked if there were any differences between Poles and Slovaks in the level of stress. Having in mind unequal sizes in both groups, they used the Mann-Whitney U test to examine those differences.
Table 1. Personality, coping styles, the feeling of threat and the feeling of stress of the aviation sector employees in Poland and Slovakia - descriptive statistics

\begin{tabular}{|c|c|c|c|}
\hline Variable & $\begin{array}{c}\mathrm{M} \\
{[\mathrm{pts}]}\end{array}$ & $\mathrm{Me}$ & SD \\
\hline \multicolumn{4}{|c|}{ Big Five personality dimensions } \\
\hline extraversion & 8.9 & 9.0 & 1.85 \\
\hline agreeableness & 10.2 & 10.0 & 2.10 \\
\hline conscientiousness & 9.9 & 10.0 & 2.34 \\
\hline emotional stability & 9.7 & 9.0 & 2.26 \\
\hline openness & 9.0 & 9.0 & 2.04 \\
\hline \multicolumn{4}{|l|}{ Coping styles } \\
\hline active coping & 8.5 & 9.0 & 3.44 \\
\hline helplessness & 6.2 & 6.0 & 3.01 \\
\hline seeking support & 4.9 & 5.0 & 2.23 \\
\hline avoidant behaviors & 6.9 & 7.0 & 2.90 \\
\hline acceptance & 2.6 & 3.0 & 1.46 \\
\hline humor & 2.4 & 2.0 & 1.29 \\
\hline turning to religion & 2.3 & 2.0 & 1.43 \\
\hline \multicolumn{4}{|l|}{ Feeling of threat } \\
\hline overall feeling of threat & 108.0 & 104.0 & 25.30 \\
\hline internal discomfort & 71.9 & 71.0 & 18.50 \\
\hline fear of current danger & 22.9 & 22.0 & 6.13 \\
\hline tendency to avoid threats & 13.5 & 13.0 & 3.44 \\
\hline \multicolumn{4}{|l|}{ Feeling of stress } \\
\hline overall feeling of stress & 53.8 & 54.0 & 8.95 \\
\hline emotional tension & 17.6 & 18.0 & 3.44 \\
\hline external stress & 18.3 & 18.0 & 3.35 \\
\hline intrapsychic stress & 18.0 & 18.0 & 3.83 \\
\hline
\end{tabular}

The analyses showed that there were few differences in stress between the 2 groups - the overall feeling of stress: Wilcoxon's test statistic $(\mathrm{W})=11$ 824.00, $\mathrm{p}=0.003$, rank biserial correlation (rbs) (effect size for Wilcoxon's test $)=0.222$; emotional tension: $\mathrm{W}=11361.00, \mathrm{p}=0.019$, rbs $=0.175$; external stress: $\mathrm{W}=11$ 152.00, $\mathrm{p}=0.041$, rbs $=0.153$; and intrapsychic stress: $\mathrm{W}=8679.00$, $\mathrm{p}=0.168, \mathrm{rbs}=0.260$. Generally, Polish employees experienced a higher level of stress $(M=54.827$, $\mathrm{SD}=7.600)$ than Slovaks $(\mathrm{M}=50.744, \mathrm{SD}=11.825)$. Also, they experienced a higher level of emotional tension $(\mathrm{M}=17.839, \mathrm{SD}=16.718)$ and external stress $(\mathrm{M}=18.577$, $\mathrm{SD}=17.449)$ than Slovaks $(\mathrm{M}=16.718, \mathrm{SD}=4.518$ and $\mathrm{M}=17.449, \mathrm{SD}=4.347$, respectively). However, the level of intrapsychic stress in both groups was similar (for Poles: 
Table 2. Relationships between personality, coping styles vs. the feeling of threat and the feeling of stress in the group of the aviation sector employees in Poland and Slovakia - Pearson's correlations coefficients

\begin{tabular}{lcccccccc}
\hline \multirow{2}{*}{ Variable } & \multicolumn{7}{c}{ Pearson's correlation coefficients } & \\
\cline { 2 - 7 } & FT & FT1 & FT2 & FT3 & FS & FS1 & FS2 & FS3 \\
\hline Extraversion & $0.158^{* *}$ & $0.183^{* * *}$ & $0.154^{* *}$ & -0.095 & $0.146^{* *}$ & $0.125^{*}$ & $0.134^{*}$ & $0.111^{*}$ \\
Agreeableness & $-0.189^{* * *}$ & $-0.219^{* * *}$ & $-0.117^{*}$ & -0.005 & $-0.193^{* * *}$ & $-0.174^{* *}$ & -0.081 & $-0.225^{* * *}$ \\
Conscientiousness & $-0.217^{* * *}$ & $-0.272^{* * *}$ & -0.090 & 0.021 & $-0.221^{* * *}$ & $-0.172^{* *}$ & $-0.109^{*}$ & $-0.266^{* *}$ \\
Emotional stability & $-0.269^{* * *}$ & $-0.291^{* * *}$ & $-0.214^{* * *}$ & -0.031 & $-0.236^{* * *}$ & $-0.200^{* * *}$ & $-0.156^{* *}$ & $-0.235^{* * *}$ \\
Openness & -0.098 & -0.073 & $-0.113^{*}$ & $-0.121^{*}$ & -0.067 & -0.059 & -0.059 & -0.053 \\
COPE 1 & 0.031 & -0.064 & $0.177^{* *}$ & $0.254^{* * *}$ & -0.051 & -0.036 & 0.016 & -0.101 \\
COPE 2 & $0.368^{* * *}$ & $0.369^{* * *}$ & $0.322^{* * *}$ & $0.145^{* *}$ & $0.350^{* * *}$ & $0.333^{* * *}$ & $0.233^{* * *}$ & $0.316^{* * *}$ \\
COPE 3 & $0.114^{*}$ & 0.044 & $0.174^{* *}$ & $0.291^{* * *}$ & -0.079 & -0.056 & -0.074 & -0.071 \\
COPE 4 & $0.174^{* *}$ & $0.182^{* * *}$ & $0.164^{* *}$ & 0.011 & $0.301^{* * *}$ & $0.259^{* * *}$ & $0.225^{* * *}$ & $0.274^{* * *}$ \\
COPE 5 & 0.014 & -0.048 & $0.109^{*}$ & $0.162^{* *}$ & 0.027 & 0.069 & 0.041 & -0.035 \\
COPE 6 & $0.142^{*}$ & $0.151^{* *}$ & $0.111^{*}$ & 0.032 & $0.159^{* *}$ & $0.177^{* *}$ & 0.094 \\
COPE 7 & $0.270^{* * *}$ & $0.287^{* * *}$ & $0.215^{* * *}$ & 0.061 & $0.176^{* *}$ & $0.151^{* *}$ & 0.092 & $0.130^{*}$ \\
\hline
\end{tabular}

${ }^{*} \mathrm{p}<0.05,{ }^{* *} \mathrm{p}<0.01,{ }^{* * *} \mathrm{p}<0.001$.

FT - overall feeling of threat, FT1 - fear of potential danger, FT2 - fear of current danger, FT3 - tendency towards threat avoidance (fear of threat subcomponents), FS - overall feeling of stress, FS1 - emotional tension, FS2 - external stress, FS3 - intrapsychic stress (feeling of stress subcomponents).

Openness - TIPI subscales, COPE 1 - active coping, COPE 2 - helplessness, COPE 3 - seeking support, COPE 4 - avoidant behaviors, COPE 5 - acceptance, COPE 6 - humor, COPE 7 - turning to religion (mini COPE subscales).

$\mathrm{M}=18.411, \mathrm{SD}=3.486$; for Slovaks: $\mathrm{M}=16.577, \mathrm{SD}=$ 4.517). In all cases, the effect size for differences was low, suggesting minor differences in average results obtained in both groups.

To evaluate the relationships between the variables, a correlation analysis was conducted and Pearson's correlation coefficient was calculated. The results of the analysis are presented in Table 2.

Statistically significant relationships between the overall feeling of threat and extraversion $(r=0.158$, $p=0.004)$, agreeableness $(r=-0.189, p<0.001)$, conscientiousness $(\mathrm{r}=-0.217, \mathrm{p}<0.001)$ and emotional stability $(\mathrm{r}=-0.269, \mathrm{p}<0.001)$ were found. A higher level of extraversion was accompanied by a higher feeling of threat, whereas higher levels of agreeableness, conscientiousness and emotional stability occurred in conjunction with a lower feeling of threat. A similar relational pattern was observed regarding the fear of potential danger whose significant correlates were extraversion $(\mathrm{r}=0.183, \mathrm{p}<0.001)$, agreeableness $(\mathrm{r}=-0.219$, $\mathrm{p}<0.001)$, conscientiousness $(\mathrm{r}=-0.272, \mathrm{p}<0.001)$ and emotional stability $(\mathrm{r}=-0.291, \mathrm{p}<0.001)$, and also regarding the fear of current danger whose significant correlates were extraversion $(\mathrm{r}=0.154$, $\mathrm{p}=0.005)$, agreeableness $(\mathrm{r}=-0.117, \mathrm{p}=0.035)$, emotional stability $(\mathrm{r}=-0.214, \mathrm{p}<0.001)$ and openness $(\mathrm{r}=-0.113, \mathrm{p}=0.041)$. Furthermore, a higher tendency towards threat avoidance was related to lower openness $(\mathrm{r}=-0.121, \mathrm{p}=0.029)$.

The personality traits were also connected with the level of experienced stress whose correlates were, similarly as with the threat level: extraversion $(\mathrm{r}=0.146$, $\mathrm{p}=0.008)$, agreeableness $(\mathrm{r}=-0.193, \mathrm{p}<0.001)$, conscientiousness $(\mathrm{r}=-0.221, \mathrm{p}<0.001)$ and emotional stability $(\mathrm{r}=-0.236, \mathrm{p}<0.001)$. A higher stress level occurred in conjunction with higher extraversion and lower agreeableness, conscientiousness and emotional stability. A similar relational pattern was observed regarding the components of the feeling of stress.

Statistically significant relationships between the feeling of threat and certain coping styles, i.e., helplessness $(\mathrm{r}=0.368, \mathrm{p}<0.001)$, seeking support $(\mathrm{r}=0.114$, $\mathrm{p}=0.039)$, avoidant behaviors $(\mathrm{r}=0.174, \mathrm{p}=0.002)$, humor $(\mathrm{r}=0.142, \mathrm{p}=0.010)$, and turning to religion $(\mathrm{r}=0.270, \mathrm{p}<0.001)$ were also observed. The higher feeling of threat was related to a higher application of these coping styles. Additionally, the fear of potential danger was connected with a higher readiness to utilize coping styles based on helplessness $(r=0.368$, $\mathrm{p}<0.001)$, avoidant behaviors $(\mathrm{r}=0.182, \mathrm{p}<0.001)$, humor $(\mathrm{r}=0.151, \mathrm{p}=0.006)$, and turning to religion $(r=0.287, p<0.001)$. Also, the fear of current 
Table 3. Predictors of the general level of stress (KSP) in the group of the aviation sector employees in Poland and Slovakia analysis of regression

\begin{tabular}{|c|c|c|c|}
\hline Variable & \multicolumn{3}{|c|}{$\beta(95 \% \mathrm{CI})$} \\
\hline \multicolumn{4}{|l|}{ Personality traits } \\
\hline extraversion & $0.076(-0.037-0.189)$ & $0.008(-0.102-0.118)$ & $-0.003(-0.112-0.106)$ \\
\hline agreeableness & $-0.069(-0.209-0.070)$ & $-0.065(-0.201-0.071)$ & $-0.054(-0.189-0.081)$ \\
\hline openness & $0.085(-0.039-0.209)$ & $0.004(-0.119-0.127)$ & $0.008(-0.114-0.130)$ \\
\hline \multicolumn{4}{|l|}{ Coping styles } \\
\hline active coping & & $-0.121(-0.257-0.015)$ & $-0.112(-0.247-0.023)$ \\
\hline helplessness & & $0.236^{* * *}(0.110-0.362)$ & $0.191^{* *}(0.062-0.321)$ \\
\hline acceptance & & $0.027(-0.092-0.146)$ & $0.036(-0.082-0.154)$ \\
\hline humor & & $0.006(-0.109-0.121)$ & $0.015(-0.099-0.129)$ \\
\hline turning to religion & & $-0.003(-0.117-0.111)$ & $-0.024(-0.138-0.090)$ \\
\hline \multicolumn{4}{|l|}{ Feeling of threat } \\
\hline general feeling of threat & & & $0.147^{\star \star}(0.036-0.258)$ \\
\hline
\end{tabular}

${ }^{*} \mathrm{p}<0.05,{ }^{* *} \mathrm{p}<0.01,{ }^{* * *} \mathrm{p}<0.001$.

M1 - personality variables, M2 - coping styles, M3 - feeling of threat.

Betas are considered as a measure of the effect size. They quantify the effect of each predictor variable to the explained variable. Therefore, they answer the question of which of the predictors have a greater effect on the explained variable regardless of the units of measurement.

danger was connected with the readiness to apply styles based on active coping $(\mathrm{r}=0.177, \mathrm{p}=0.001)$, helplessness $(\mathrm{r}=0.322, \mathrm{p}<0.001)$, seeking support $(\mathrm{r}=0.174$, $\mathrm{p}<0.002)$, avoidant behaviors $(\mathrm{r}=0.164, \mathrm{p}=0.003)$, acceptance $(r=0.109, \mathrm{p}=0.049)$, humor $(\mathrm{r}=0.111$, $\mathrm{p}=0.045)$, and turning to religion $(\mathrm{r}=0.215, \mathrm{p}<0.001)$. The tendency towards threat avoidance was connected with a more frequent use of a style based on active coping $(\mathrm{r}=0.254, \mathrm{p}<0.001)$, helplessness $(\mathrm{r}=0.145$, $\mathrm{p}=0.009)$, seeking support $(\mathrm{r}=0.291, \mathrm{p}<0.001)$, and acceptance $(\mathrm{r}=0.162, \mathrm{p}=0.003)$.

Relationships between the feeling of stress and coping styles based on helplessness $(r=0.350, p<0.001)$, avoidant behaviors $(\mathrm{r}=0.301, \mathrm{p}<0.001)$, humor $(\mathrm{r}=0.159, \mathrm{p}=0.004)$, and turning to religion $(\mathrm{r}=0.176$, $\mathrm{p}=0.001$ ) were also found. A higher level of stress occurred in conjunction with a higher readiness to use these coping styles.

Additionally, an analysis of the relationship between the feeling of danger and the feeling of stress showed a statistically significant correlation between them. A higher feeling of danger was accompanied by a higher level of stress.
A multiple regression analysis was then performed in order to determine which of the variables allow a prediction of the feeling of stress. One by one, the personality variables (M1), coping styles (M2) and the feeling of threat (M3) were added to the regression model while observing the changes in the variance explained by the model. For each of the created models, the variance inflation factors (VIFs) and Durbin-Watson statistics equaled 2 , suggesting that the collinearity and autocorrelation of the regression residuals did not disturb the model parameter values. The results of the analysis are presented in Table 3.

The regression analysis indicated that personality variables do not allow for predicting the level of stress $\left(\mathrm{R}^{2}=0.076, \mathrm{~F}(5,320)=5.230, \mathrm{p}<0.001\right)$. Including the variables connected with coping in the regression model caused a statistically significant increase in the variance explained by the model $\left(\Delta \mathrm{R}^{2}=0.137, \mathrm{~F}(7,313)=7.781, \mathrm{p}<0.001\right)$, explaining $21 \%$ of the variability in the feeling of stress $\left(R^{2}=0.213\right.$, $\mathrm{F}(12,313)=7.040, \mathrm{p}<0.001)$. In the third step, including the feeling of threat caused a further increase in the explained variance $\left(\Delta \mathrm{R}^{2}=0.017, \mathrm{~F}(1,312)=6.811\right.$, 
$\mathrm{p}=0.009)$. The final model explained $23 \%$ of the variance in the feeling of stress $\left(\mathrm{R}^{2}=0.229, \mathrm{~F}(13,312)=7.141\right.$, $\mathrm{p}<0.001)$. In this model, the helplessness-oriented style $(\beta=0.191$, standard error [s.e.] $=0.20, \mathrm{t}=2.906$, $\mathrm{p}=0.004)$, avoidant behaviors $(\beta=0.244$, s.e. $=0.20$, $\mathrm{t}=3.804, \mathrm{p}<0.001)$ and the feeling of threat $(\beta=0.147$, s.e. $=0.20, t=2.610, p=0.009)$ were significant predictors of the feeling of stress, and their high level corresponded with a higher level of stress.

\section{DISCUSSION}

The study presented in this paper provided interesting results about the relationships between the sense of stress and threat, personality variables, and coping styles. A positive correlation of extraversion with both the feeling of threat and the feeling of stress, which seems to be a more "constant" state, is an interesting result. The orientation towards interacting with others, maintaining social contact, and a high level of activity co-occur with a more frequent or more intensive feeling of threat and the feeling of stress. It may result from a more frequent exposure of extraverts to social interactions. Such interactions may be related to more intensive experiencing situations that are potentially difficult and overwhelming. Also, a higher level of emotional stability (a lower level of neuroticism), conscientiousness, and agreeableness of aviation sector employees are related to a lower level of the feeling of threat. Such a personality profile seems especially recommended in a sector where professional risk is directly related to the risk of health loss. The authors observed a similar connection for the correlation between extraversion and the general feeling of stress. Consistent with the feeling of threat, extraverted persons will experience a higher level of stress than more introverted individuals.

Despite many controversies concerning the relationships between personality determinants and the experienced psychological cost of work, reference can be made to the study results which prove that emotional stability, low psychoticism, and an internal locus of control are related to choosing more assertive strategies of acting and coping with stress. Extraverts often choose intuitive styles of dealing with stress and, for this reason, they can hurt others because they act instinctively without analyzing the consequences of their actions [24,25].

The feeling of threat in the studied group is significantly related to the following styles of coping with stress: helplessness, emotional support, avoidant behaviors, humor, and turning to religion. The respondents representing the aviation sector used activities related to the coping styles mentioned above while experiencing a more intense feeling of threat. These actions, according to the authors of the diagnostic instrument, are not proactive, but they are an expression of avoidant strategies, seeking support, and concentrating on emotions $[26,27]$. Coping through being in touch with emotions can be beneficial but rather from a short-term perspective, while the lack of emotional expression or "bottling the emotions up" stands for counterproductive coping.

This study also showed a connection between the level of experienced stress and coping styles based on helplessness, avoidant behaviors, humor, and turning to religion. In the context of these dependencies, the intensity of emotional-cognitive cost, in the form of experienced stress and threat resulting from non-constructive activities which generate an additional psychological loss, seems to be crucial. As stated by Scheier and Carver [9], humor is a substitute action which provides a distraction from the stressor and the source of danger but does not permanently relieve the level of agitation. In their opinion, every strategy that does not help challenge the source of stress in an engaged and confrontative way is less effective in coping with stress. Turning to religion seems to be controversial: from the perspective of Costa and McCrae's studies [13-15], it is a beneficial strategy of coping with psychological tension, defined as a strategy of searching for emotional support, which can significantly influence positive redefinition and development, and become an active form of coping.

The biggest surprise was the result of the regression analysis in the context of personality dimensions. In the studied group, the level of experienced stress does not depend on the personality profile, i.e., personality traits do not predict the dependent variable. It is impossible to prove the cause-and-effect relationships between them. In this context, it is crucial to make the management of companies in this sector aware of the importance of learned or preferred techniques and styles of solving difficult situations: these techniques determine the feeling of stress. The authors found out that avoidant behaviors, i.e., avoiding the source of stress, withdrawal (avoiding confrontation), monitoring the source of stress, and experiencing helplessness facilitate an intensification of experienced stress.

The presented results should inspire employers to develop procedures that would allow them to shape effective strategies helpful in regulating and decreasing feelings of stress and threat. In terms of sustainability, such 
actions may provide favorable conditions for promoting self-development of employees, nurturing healthy functioning, and increasing the motivation to work effectively [1]. Also, the early identification of the employees characterized by deficits in the coping mechanism may support the implementation of assistance activities to increase their well-being.

This idea highly corresponds to the issues central to the sustainable development of the organization. As described by Tutak et al. [28], the sustainability of a company is a phenomenon conditioned by human factors and concerns related to the organization's technical facilities and environment. Therefore, dealing with employee's troubles is considered a key factor for promoting the sustainable development of both organizations in general and their employees. In this case, the analysis of work conditions, and the atmosphere in the aviation sector (e.g., the feelings of stress and threat experienced by employees) are of immense importance for creating both a constructive policy in the field of human resource management and providing chances for sustainable development of the company. Also, it allows for creating an opportunity for employees to learn how to deal with negative emotional responses at work [29].

The lack of predictive potential regarding the personality dimensions also hypothetically proves the high uniqueness of the group of employees of the aviation sector, compared to other groups. For example, recent studies have shown that some of the personality traits, mainly neuroticism, openness, and conscientiousness, are predictors of the stress occurring while working with robots [30]. In the case of employees of the aviation sector, the authors did not find such relationships.

Similarly, the results have revealed that the feeling of threat intensifies the feeling of stress. These results are not surprising, considering the results accumulated in the field of health psychology. It is well-known that using more active coping strategies is connected with a higher level of one's self-esteem and self-efficacy, and an internal locus of control. According to Schwarzer and Taubert [30], proactive coping connected with challenges and gathering resources allows for effective stress management. Proactivity helps to cope with future events, detect potential stressors, initiate their assessment, take efforts, and receive feedback about taken actions.

In the context of strengthening personal resources of employees of the aviation sector, and of developing prophylactic measures minimizing the risk of chronic professional stress and burnout, focus should be on skills related to monitoring stressors and strengthening proactivity in difficult or threatening situations [31]. Therefore, providing any soft skills training of resilience, development of mindfulness or awareness of one's emotional states, and increasing the readiness to confront unpleasant or burdensome cognitive content, are recommended. Training and support in cognitive behavioral techniques whose regular application supports the development of agency and the feeling of control, while facing difficult situations, would be recommended as well.

\section{CONCLUSIONS}

The study presented in this paper was conducted before the COVID-19 pandemic which makes it impossible to generalize the conclusions in the studied sector to bigger groups of employees in this sector. However, the suggestion of avoiding the direct association of employees' personality profiles with the experiencing of stress, and recommending greater concentration on developing constructive coping styles among employees instead, seem to be a universal recommendation. In this case, creating an opportunity for employees to learn how to deal with negative emotional responses at work seems to be a key factor for promoting the sustainable development of organizations in general, and their employees.

A significant limitation of the study was its method: using questionnaires. These methods provide limited data. However, the authors did not find a more effective method enabling them to reach a bigger group of employees of such a "closed" sector.

The authors' scientific interests are connected with attitudes, behaviors and relationships between employees and their professional environment in the wide context of work 4.0, especially in the sectors of the latest technologies, automation and industry 4.0. Further studies are focusing on the adaptation of scientific instruments to the specific qualities of this sector, especially through concentrating on the character of work in the environment with the latest technologies, and the challenges connected with them.

\section{REFERENCES}

1. Manuti A, Giancaspro ML. People Make the Difference: An Explorative Study on the Relationship between Organizational Practices, Employees' Resources, and Organizational Behavior Enhancing the Psychology of Sustainability and Sustainable Development. Sustain. 2019;11:149, https://doi.org/10.3390/su11051499. 
2. Tokarz A, Malinowska D. From Psychological Theoretical Assumptions to New Research Perspectives in Sustainability and Sustainable Development: Motivation in the Workplace. Sustain. 2019;11:2222, https://doi.org/10.3390/ su11082222.

3. Lazarus RS, Folkman S. Stress, appraisal and coping. New York: Springer - Verlag; 1984.

4. Lazarus RS. From psychological stress and emotions: A history of changing outlooks. Annu Rev Psychol. 1993;44: 1-21, https://doi.org/10.1146/annurev.ps.44.020193.000245.

5. Maslach Ch, Leiter MP. Early Predictors of Job Burnout and Engagement. J Appl Psychol. 2008;93(3):498-512, https://doi.org/10.1037/0021-9010.93.3.498.

6. Maslach Ch, Leiter MP. Banishing Burnout: Six Strategies for Improving Your Relationship with Work. Warszawa: Oficyna Wolters Kluwer Business; 2010.

7. Chodkiewicz J. Health Psychology. Łódź: Wydawnictwo Wyższej Szkoły Humanistyczno-Ekonomicznej; 2005.

8. Maslach Ch, Leiter MP. The Truth About Burnout: How Organizations Cause Personal Stress and What to Do About It. Warszawa: Wydawnictwo Naukowe PWN; 2011.

9. Scheier MF, Carver CS. A model of behavioral self-regulation: Translating intention into action. In: Berkowitz L, editor. Advances in experimental social psychology, Vol. 21. Social psychological studies of the self: Perspectives and programs. Elsevier: Academic Press; 1988. p. 303-46.

10. Buruck G, Dörfel D, Kugler J, Brom SS. Enhancing well-being at work: The role of emotion regulation skills as personal resources. J Occup Health Psychol. 2016;21(4): 480-93, https://doi.org/10.1037/ocp0000023.

11. Hobfoll SE, Johnson RJ, Ennis N, Jackson AP. Resource loss, resource gain, and emotional outcomes among inner city women: Correction to Hobfoll et al. J Pers Soc Psychol. 2003;85(2):248, https://doi.org/10.1037/0022-3514. 85.2.248.

12. Häusser JA, Mojzisch A, Niesel M, Schulz-Hardt S. Ten years on: A review of recent research on the Job demandcontrol(-Support) model and psychological well-being. Work Stress. 2010;24:1-35, https://doi.org/10.1080/0267 8371003683747.

13. McCrae RR, Costa PT Jr. Personality trait structure as a human universal. Am Psychol. 1997;52(5):509-16, https://doi.org/10.1037/0003-066X.52.5.509.

14. McCrae RR, Costa PT Jr, Gary GK Persons, places and personality: career assessment using the revised NEO Personality Inventory. J Career Assess. 1997;3(2):123-39, https://doi.org/10.1177/106907279500300202

15. McCrae RR, Costa PT Jr. Personality in adulthood. A five-factor theory perspective. London, New York: The Guilford Press; 2003.
16. Zawadzki B, Strelau J, Szczepaniak P, Śliwińska M. Personality Inventory NEO-FFI by Paul T. Costa Jr and Robert R. McCrae. Polish adaptation. Warszawa: Pracownia Testów Psychologicznych; 2007.

17. Sorokowska A, Słowińska A, Zbieg A, Sorokowski P. Polish adaptation of Ten Item Personality Inventory (TIPI) - TIPI-PL - standard and online version. Wocław: WrocLab; 2014.

18. Mamcarz P. Psychology of threat in high risk professions. Lublin: Wydawnictwo Katolickiego Uniwersytetu Lubelskiego; 2016.

19. Plopa M, Makarowski M. Feeling of Stress Questionnaire. Warszawa: Vizja Press\&IT; 2010.

20. Juczyński Z, Ogińska-Bulik N. Instruments of stress and coping measurement. Mini-cope. Warszawa: Pracownia Testów Psychologicznych PTP; 2009.

21. Gosling SD, Rentfrow PJ, Swann WB Jr. A very brief measure of the Big-Five personality domains. J Res Pers. 2003;37:504-28.

22. Carver CS, Scheier MF, Weintraub JK. Assessing coping strategies: A theoretically based approach. J Pers Soc Psychol. 1989;56(2):267-83, https://doi.org/10.1037/00223514.56.2.267.

23. JASP Team [Internet]. [cited 2021 May 31]. Amsterdam: JASP - Computer Software (Version 0.14.1), 2020. Available from: https://jasp-stats.org.

24. Buhler KE, Land T. Burnout and Personality in Intensive care: An Empirical Study. Hosp Top Res Persp Health. 2003;81(4):5-12, https://doi.org/10.1080/0018586030959 8028.

25. Syroka J. Burnout: individual and social costs. In: Witkowski S.A. (ed.). Psychological indicators of success in management. Vol. VI. Wrocław: Wydawnictwo Uniwersytetu Wrocławskiego; 2003.

26. Ogińska-Bulik N. Perceived job stress, personality traits and burnout syndrome in police officers. Pol J Appl Psychol. 2005;3(1):7-24.

27. Maree JG, Di Fabio A. Integrating Personal and Career Counseling to Promote Sustainable Development and Change. Sustain. 2018;10:4176, https:/doi.org/10.3390/ su10114176.

28. Tutak M, Brodny J, Dobrowolska M. Assessment ofWork Conditions in a Production Enterprise - A Case Study. Sustain. 2020;12:5390, https://doi.org/10.3390/su12135390.

29. Kucharčíková A, Mičiak M. Human Capital Management in Transport Enterprises with the Acceptance of Sustainable Development in the Slovak Republic. Sustain. 2018;10:2530, https://doi.org/10.3390/su10072530.

30. Schwarzer R, Taubert S. Tenacious goal pursuits and striving toward personal growth: Proactive coping. In: Fryden- 
berg E, editor. Beyond coping: Meeting goals, visions and challenges. London: Oxford University Press; 2002.

31. Dobrowolska M, Flakus M, Ślazyk-Sobol M, Wawoczny A. Strengthening Professional Efficacy Due to Sustainable
Development of Social and Individual CompetencesEmpirical Research Study among Polish and Slovak Employees of the Aviation Sector. Sustain. 2020;12(17):6843, https://doi.org/10.3390/su12176843.

This work is available in Open Access model and licensed under a Creative Commons Attribution-NonCommercial 3.0 Poland License - http://creativecommons.org/licenses/by-nc/3.0/pl/deed.en. 